\title{
Oral vitamin A supplementation in very low birth weight neonates: a randomized controlled trial
}

\author{
Sriparna Basu ${ }^{1,2}$ (D) $\cdot$ Parul Khanna $^{1} \cdot$ Ragini Srivastava $^{3} \cdot$ Ashok Kumar $^{1}$ \\ Received: 4 May 2019 / Revised: 10 June 2019 / Accepted: 11 June 2019 / Published online: 17 June 2019 \\ (C) Springer-Verlag GmbH Germany, part of Springer Nature 2019
}

\begin{abstract}
This randomized double-blind placebo-controlled trial evaluated the effects of early postnatal oral vitamin A supplementation (VAS) in 196 inborn very-low birth weight (VLBW) infants requiring respiratory support at $24 \mathrm{~h}$ of age. Eligible infants were randomized to receive aqueous syrup of vitamin A (10,000 IU of retinol/dose; $n=98)$ or placebo $(n=98)$ on alternate days for 28 days. Primary outcome variable was composite incidence of all-cause mortality and/or oxygen requirement for 28 days. Secondary outcome variables were safety/tolerability of VAS, serum retinol concentration at recruitment and day 28, duration of oxygen requirement and respiratory support and incidences of complications. On intention-to-treat analysis, composite incidence of all-cause mortality and oxygen requirement for 28 days was significantly lower in vitamin A group (relative risk (95\% confidence interval), 0.440 (0.229-0.844); $p<0.05$, number needed to benefit, 7). Requirement and duration of oxygen supplementation and non-invasive respiratory support, incidences of late-onset sepsis, patent ductus arteriosus, and duration of hospital stay were also significantly lower in vitamin A group. Serum retinol concentration improved significantly after VAS. No major adverse effect was observed.

Conclusions: Early postnatal oral VAS was associated with better composite outcome of all-cause mortality and oxygen requirement without any major adverse effects.

Clinical Trial Registration: Clinical Trials Registry of India (CTRI/2017/03/008131).

\section{What is Known:}

- Postnatal intramuscular vitamin A supplementation improves the survival, respiratory outcome and other morbidities in very low birth weight neonates without major adverse effects.

- Limited studies on oral vitamin A supplementation did not document substantial benefits.

What is New:

- Early postnatal alternate-day oral vitamin A supplementation at the dose of 10,000 IU/dose for 28 days improves the composite outcome of death and oxygen requirement in very low birth weight neonates with respiratory distress

- No major adverse effects were documented
\end{abstract}

Keywords Neonate · Oral · Very low birth weight · Vitamin A supplementation

Communicated by Patrick Van Reempts

Sriparna Basu

drsriparnabasu@rediffmail.com

Parul Khanna

khanna.paru190@gmail.com

Ragini Srivastava

raginibiochembhu@gmail.com

Ashok Kumar

ashokkumar_bhu@hotmail.com
1 Neonatal Unit, Department of Pediatrics, Institute of Medical Sciences, Banaras Hindu University, Varanasi, India

2 Department of Neonatology, All India Institute of Medical Sciences, Rishikesh, India

3 Department of Biochemistry, Institute of Medical Sciences, Banaras Hindu University, Varanasi, India 


$\begin{array}{ll}\text { Abbreviations } \\ \text { BW } & \text { Birth weight } \\ \text { BPD } & \text { Bronchopulmonary dysplasia } \\ \text { CI } & \text { Confidence interval } \\ \text { CPAP } & \text { Continuous positive airway pressure } \\ \text { CTRI } & \text { Clinical Trial Registry of India } \\ \text { DDST } & \text { Denever Developmental Screening Test } \\ \text { EOS } & \text { Early-onset sepsis } \\ \text { HFNC } & \text { High flow nasal cannula } \\ \text { h s - } & \text { Hemodynamically significant patent ductus } \\ \text { PDA } & \text { arteriosus } \\ \text { IQR } & \text { Inter quartile range } \\ \text { IM } & \text { Intramuscular } \\ \text { IV } & \text { Intravenous } \\ \text { IVH } & \text { Intraventricular hemorrhage } \\ \text { LOS } & \text { Late-onset sepsis } \\ \text { LMIC } & \text { Low and middle income countries } \\ \text { MV } & \text { Mechanical ventilation } \\ \text { NICHD } & \text { National Institute of Child Health and Human } \\ & \text { Development } \\ \text { NEC } & \text { Necrotizing enterocolitis } \\ \text { NICU } & \text { Neonatal intensive care unit } \\ \text { NNTB } & \text { Number needed to treat for benefit } \\ \text { OGT } & \text { Orogastic tube } \\ \text { PVL } & \text { Periventricular leukomalacia } \\ \text { PMA } & \text { Post-menstrual age } \\ \text { RR } & \text { Relative risk } \\ \text { RDS } & \text { Respiratory distress syndrome } \\ \text { ROP } & \text { Retinopathy of prematurity } \\ \text { VLBW } & \text { Very low birth weight } \\ \text { VAS } & \text { Vitamin A supplementation } \\ & \end{array}$

\section{Introduction}

Vitamin A or retinol is essential for normal embryogenesis, immune response, visual functioning, genetic expression, and hematopoiesis [17]. It also regulates cellular growth and differentiation in the lungs, maintains integrity of respiratory epithelium, and helps in surfactant synthesis [3,11]. Vitamin A deficiency (VAD) may lead to recurrent infections and an increased risk of bronchopulmonary dysplasia (BPD) [13]. In laboratory animals, necrotizing tracheobronchiolitis and squamous metaplasia pulmonary epithelium caused by VAD could be reversed after restoration of adequate vitamin A status [9]. Similar changes observed in ventilated infants with BPD lead to the speculation that early vitamin A supplementation (VAS) might be beneficial in high-risk infants [9].

Vitamin A is primarily transported to the fetus during third trimester of pregnancy leading to limited hepatic vitamin A reserves in preterm infants [36]. High prevalence of preterm births as well as maternal VAD in low and middle income countries (LMIC) compound the problem further [6, 38].
Various studies have documented an association of postnatal intramuscular (IM)-VAS with reduced mortality and/or oxygen requirement at 1 month and lower incidences of long-term neurodevelopmental disability in preterm very low birth weight (VLBW) infants $[11,16,21,22,33,34]$. The possibility that IM-VAS may ameliorate other complications of prematurity, such as retinopathy of prematurity (ROP), intraventricular hemorrhage (IVH), sepsis, hemodynamically significant patent ductus arteriosus (hs-PDA), and necrotizing enterocolitis (NEC) has also been suggested [11].

Most of the studies have used multiple IM injections of vitamin A with doses ranging from 5000 to $10,000 \mathrm{IU} /$ dose $[16,21,22,33,34]$. Although no serious adverse events were reported with the use of this dose, repeated IM injections are painful, difficult to administer in poor muscle mass, associated with potential risk of secondary infection, and often unacceptable to the parents. Moreover, high cost and limited availability of injectable vitamin A preparations further preclude the use of IM vitamin A injections [10]. Intravenous (IV) supplementation is not suitable for its invasive nature and risk of infection [30].

Very few studies have used oral vitamin A as a preventive measure for mortality or BPD, and the results are not conclusive $[8,36]$. There is no consensus regarding the oral dose of vitamin A to be used. Recommended supplementation of vitamin A for VLBW infants ranges from 1000 to $1500 \mathrm{IU} / \mathrm{Kg} /$ day, irrespective of the route of administration [7], though higher doses have been recommended for prevention of morbidity and mortality [24]. Previous authors have used an oral dose of $5000 \mathrm{IU} /$ day of vitamin A without any clinical or biochemical evidence of vitamin A toxicity [36].

The present study was conducted to investigate the effect of early postnatal oral VAS in VLBW infants with respiratory distress.

\section{Methods}

This randomized double-blind placebo-controlled trial was conducted at a tertiary care teaching hospital of India, over 20 months (January 2016 to August 2017) after obtaining approval from Institute Ethics Committee. Written informed consents in local language were taken from all parents before inclusion. The trial was registered with Clinical Trial Registry of India (Registration No: CTRI/2017/03/008131).

\section{Study population}

Inborn, VLBW (birth weight $(\mathrm{BW})<1500 \mathrm{~g}$ ) neonates admitted in NICU and requiring respiratory support in the form of oxygen inhalation through nasal prongs or head box, continuous positive airway pressure (CPAP), high flow nasal cannula (HFNC), or mechanical ventilation (MV) at the age of $24 \mathrm{~h}$, 
were included. Neonates with major congenital malformation, any life-threatening condition where immediate oral feeding was contraindicated such as reversal of umbilical artery enddiastolic blood flow on antenatal Doppler, perinatal asphyxia with moderate to severe hypoxic ischemic encephalopathy, shock with escalating doses of vasopressors, recurrent seizures, and suspected inborn errors of metabolism were excluded.

\section{Randomization and allocation}

Randomization into vitamin A or placebo group was done using random permuted blocks of 4,6 , and 8 , prepared by an independent statistician not involved in the study. Allocation into vitamin A or placebo group was done using serially numbered opaque and sealed envelopes by on-duty residents who were appropriately trained for the process beforehand. Allocation concealment was maintained throughout the study.

\section{Method of blinding/masking}

Vitamin A and placebo oral solutions were supplied in identical bottles of $20 \mathrm{~mL}$ with dropper marked at $1 \mathrm{~mL}$. Vitamin A bottle contained 10,000 IU of retinol/mL in aqueous base, whereas placebo contained only base solution without any drug. The color and smell of the solution contained in the bottles were identical. Treating physicians, nursing staffs, and the parents were unaware about the composition of the bottles. Oral administration was done by nursing staff during hospital stay and later by parents at home, if discharged. Both the groups were trained beforehand for the procedure.

\section{Method of administration of the intervention}

Neonates in the vitamin A and placebo groups received $1 \mathrm{~mL}$ of syrup vitamin A or placebo on alternate day for 28 days, starting at $24 \mathrm{~h}$ of life (total 14 doses). In neonates on parenteral and/or orogastic tube (OGT) feeding, the solution was administered through OGT followed by a chasing with $1 \mathrm{~mL}$ sterile water. OGT was not aspirated later unless the neonate developed abdominal distension (abdominal girth increasing by $2 \mathrm{~cm}$ from the previous measurement). In infants on cup/ breastfeed, the solution was put directly into the neonate's mouth and feeding was continued for a few minutes. If the neonate vomited within $5 \mathrm{~min}$, the dose was repeated.

\section{Outcome variables}

Primary outcome variable was composite incidence of allcause mortality and/or oxygen requirement for 28 days, measured at day 28 of life. Secondary outcome variables were safety and tolerability of high-dose VAS, serum retinol concentration at recruitment and day 28 , total duration of oxygen requirement, and respiratory support by $\mathrm{CPAP} / \mathrm{HFNC} /$ $\mathrm{MV}$ and incidences of complications such as sepsis, echocardiography-confirmed hs-PDA, NEC (Bell stage II and beyond), IVH (grade II and beyond), periventricular leukomalacia (PVL), and ROP. All-cause mortality was measured again at post-menstrual age (PMA) of 36 weeks along with BPD.

\section{Clinical work up}

Maternal and neonatal details were recorded. Neonates were examined thoroughly after birth and anthropometric details were recorded. Intra-uterine growth categorization was done as per INTERGROWTH 21ST standards [35].

Study neonates were managed according to our NICU protocol. Initial nutritional support was provided by IV fluids and parenteral nutrition. Enteral feeding with expressed breast milk was started through OGT as soon as the infant became hemodynamically stable. Antibiotics were started in presence of risk factors for sepsis and modified/stopped as per clinical condition, sepsis screen, and blood culture reports. The nature of respiratory support was guided by Downe score [12], chest $\mathrm{X}$-ray, and arterial blood gas parameters under strict monitoring with pulse oximeter for a saturation target of 90-94\%. Caffeine was started if the infant was on CPAP/HFNC/MV. Surfactant replacement therapy (Curosurf $200 \mathrm{mg} / \mathrm{kg}$ initially, repeated on deterioration) was given if the neonate showed clinical and radiological evidence of respiratory distress syndrome (RDS). None of the neonates was given any steroid (injectable or inhalational), diuretics, or azithromycin to prevent BPD.

During hospital stay, infants were observed for the development of sepsis, hs-PDA, acute kidney injury (AKI), neonatal hyperbilirubinemia (NNH), IVH, NEC, PVL, BPD [20], and ROP [19]. Hs-PDA was treated with IV paracetamol $15 \mathrm{mg} / \mathrm{kg} /$ dose 6 hourly for $72 \mathrm{~h}$. Cranial ultrasound was done at recruitment and at days 3, 7,28, and at clinical suspicion for detection of IVH and PVL. Germinal matrix-intraventricular hemorrhage was graded as per Papile et al. [28]. ROP screening was done at 4 weeks of postnatal age and repeated as per the advice of the ophthalmologist.

Infants were observed for the features of raised intracranial pressure or mucocutaneous lesions suggestive of hypervitaminosis A. If the infant developed NEC or frank gastrointestinal hemorrhage at any time, oral vitamin A/placebo supplementation was stopped, and the infant was managed appropriately. Progress during the hospital stay and outcome were noted. If discharged earlier, parents were contacted telephonically to remind for vitamin A administration and to note occurrence of side effects, if any. Infants were called after completion of 28 days for estimation of serum retinol. Study 
neonates are currently being followed up for growth, development, and morbidity.

\section{Estimation of serum retinol}

Peripheral venous blood samples were taken at recruitment and on day 28 of life for estimation of serum retinol. Sampling was clustered with other investigations. Serum was separated immediately by centrifugation and stored at $60{ }^{\circ} \mathrm{C}$ until further analysis. Retinol concentration was measured by spectrophotometric method of Bessey et al. [5].

\section{Sample size calculation}

As per the record of our NICU, the combined incidence of death and BPD (defined as oxygen requirement for $\geq 28$ days) in VLBW neonates requiring respiratory support at $24 \mathrm{~h}$ of age in the previous year was $64 \%$. Assuming a similar incidence and expecting a relative risk reduction of $20 \%$ in vitamin A group compared with placebo, with a confidence level of $95 \%$ and power of $80 \%$, a minimum total sample size calculated was 178 using online power/sample size calculator (http:// www.stat.ubc.ca/ rollin/stats/ssize/b2.html). Expecting a $10 \%$ attrition rate, the final total sample size estimated was 196, with 98 in each group.

\section{Statistical analysis}

The statistical program SPSS version 16.0 (SPSS Inc., Chicago, IL) was used for data entry and analysis. Independent samples $T$ test, Mann-Whitney $U$ test, chisquare test and Fisher exact test were used to compare continuous and categorical variables between groups. Relative risk (RR) with $95 \%$ confidence interval (CI), and number needed to treat for benefit (NNTB) were calculated for outcome variables using MEDCALC® (www.medcalc.org/calc/relative_ risk.php). Survival analysis of the study neonates was done using Kaplan Meier survival plot analysis. A $p$ value of $<0.05$ was considered statistically significant.

\section{Results}

\section{Flow of participants}

One hundred and ninety-six neonates were randomized into vitamin A $(n=98)$ and placebo $(n=98)$ groups. Allocated intervention was started in all. Eighty-five (85/98) infants in the vitamin A group and 76 (76/98) infants in placebo group completed the intervention. The statistical analysis was done on intention-to-treat basis (Fig. 1).

\section{Profile of the study population}

Both the groups were comparable with respect to maternal and neonatal characteristics (Table 1). Mean BW of vitamin A and placebo groups were $1185 \pm 194$ and $1163 \pm 181 \mathrm{~g}$, respectively; and mean gestational ages (GA) were $30.9 \pm 2.9$ and $30.7 \pm 2.7$ weeks, respectively. There was no difference in distribution of gender, intrauterine growth patterns, Apgar scores, Downe score, surfactant, and $\mathrm{SpO}_{2}$ at recruitment between the groups. However, requirement of paracetamol therapy for hs-PDA was significantly less in vitamin A group (7/98 in vitamin A vs. 20/98 in placebo; $p<0.05)$. The most common cause of respiratory distress was RDS (57/98 in vitamin A and 59/98 in placebo), followed by early-onset sepsis (EOS) with intrauterine pneumonia (30/98 in vitamin A and $27 / 98$ in placebo). Transient tachypnea of newborn and meconium aspiration syndrome were responsible in a minor percentage of cases (3/98 and 1/98 vs. 4/98 and 1/98 in vitamin A and placebo groups, respectively). Both the groups had similar other sources of vitamin A from parenteral nutrition and milk feeds.

\section{Outcome variables}

Outcome variables are summarized in Table 2. Composite incidence of all-cause mortality and oxygen requirement for 28 days were significantly lower in vitamin A group, compared with placebo (RR (95\% CI), 0.440 (0.229-0.844); $p<0.05$, NNTB 7). Among secondary outcome variables, although there was no difference in EOS between the groups, the incidence of late-onset sepsis (LOS) was significantly lower in vitamin A group (RR (95\% CI), 0.564 (0.346-0.918); $p<0.05$, NNTB 7). Klebsiella pneumoniae was the organism most commonly grown both for EOS and LOS in either group. Incidence of hs-PDA was significantly higher in placebo than vitamin A group (RR (95\% CI), 0.350 (0.155-0.789); $p<0.05$, NNTB 8). Though incidence of BPD at 36 weeks' PMA was less in vitamin A than placebo (2/98 vs. 9/98), the difference was not statistically significant. Other complications and total number of all-cause mortality at 36 weeks PMA were similar between the groups.

\section{Respiratory support}

Compared to placebo, requirement, and duration of oxygen supplementation and non-invasive respiratory support by CPAP/HFNC were significantly less in vitamin A group. Though number of infants requiring $\mathrm{MV}$ was less in vitamin A compared with placebo (17/98 vs. 25/98), the difference was not statistically significant. The duration of MV was also similar (Table 3). 


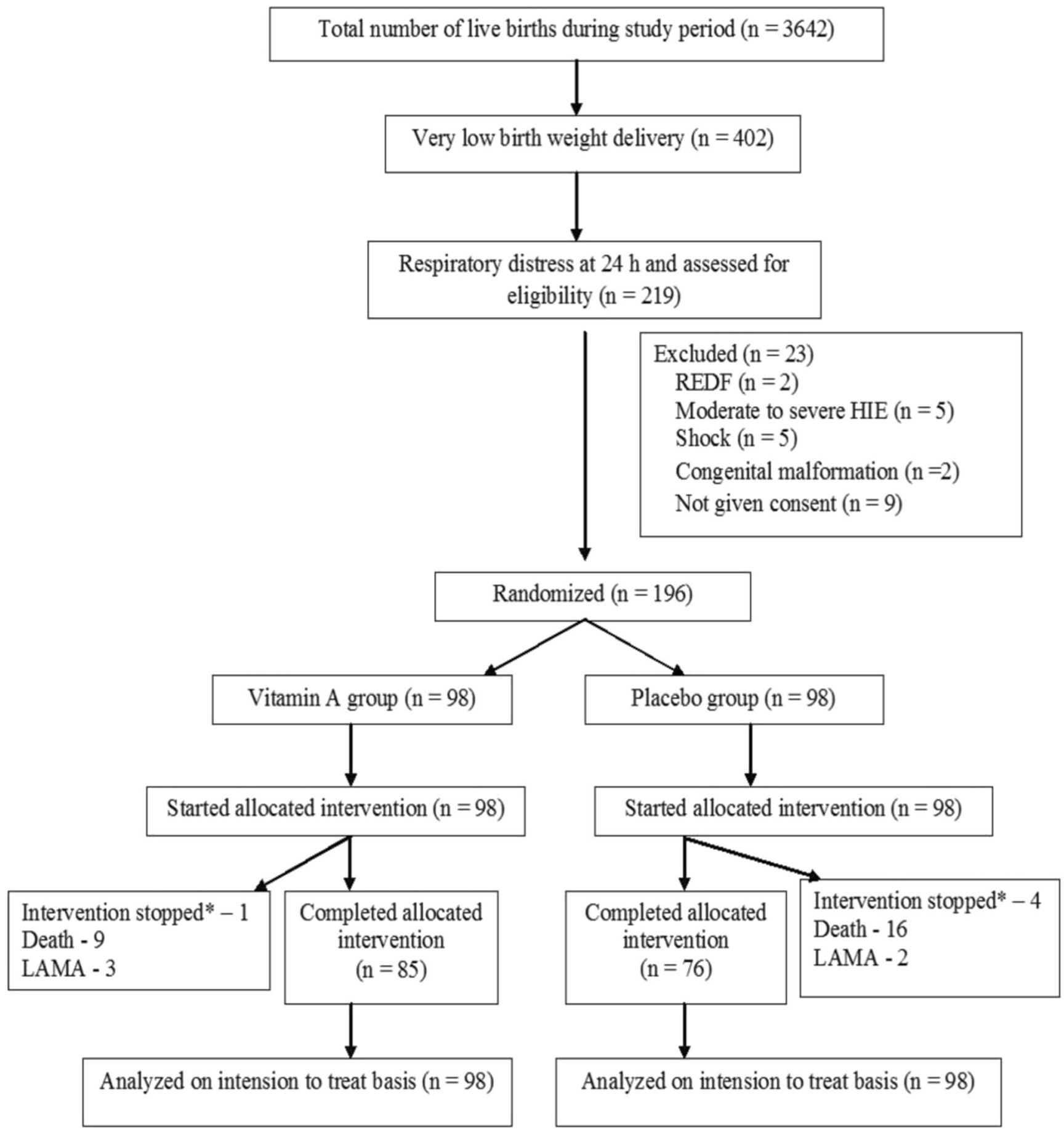

Fig. 1 Flow of participants. *Developed necrotizing enterocolitis stage II. REDF—Reversed end-diastolic flow; LAMA—Left against medical advice for financial constraints

\section{Adverse effects of intervention and outcome}

No major adverse effect was observed in either group. Transient vomiting was observed in three neonates in vitamin A and five neonates in placebo group; $p>0.05$. None of the infants in either group had diarrhea, bulging fontanel, or mucocutaneous lesions.
Interventions were stopped in one and four infants in vitamin A and placebo groups, respectively, for the development of NEC stage II. All of these neonates recovered without any sequelae.

In vitamin A group, 9/98 infants expired and 86/98 were discharged. In placebo group, 16/98 infants expired and 80/98 were discharged $(p>0.05)$. All the deaths were because of 
Table 1 Maternal and neonatal characteristics

\begin{tabular}{|c|c|c|c|}
\hline Characteristic & Vitamin A $(n=98)$ & Placebo $(n=98)$ & $P$ value \\
\hline \multicolumn{4}{|l|}{ Maternal } \\
\hline Maternal age (years) $($ mean $\pm \mathrm{SD})$ & $25.4 \pm 4.2$ & $25.7 \pm 3.9$ & $0.634(\mathrm{NS})^{\mathrm{a}}$ \\
\hline Antenatal care ( $\geq 3$ antenatal visits), $n(\%)$ & $64(65.3)$ & $66(67.3)$ & $0.879(\mathrm{NS})^{\mathrm{c}}$ \\
\hline $\mathrm{PIH} /$ preeclampsia, n (\%) & $23(23.5)$ & $21(21.4)$ & $0.864(\mathrm{NS})^{\mathrm{c}}$ \\
\hline Eclampsia, $n(\%)$ & $15(15.3)$ & $14(14.3)$ & $1.000(\mathrm{NS})^{\mathrm{c}}$ \\
\hline POL, $n(\%)$ & $37(37.8)$ & $32(32.7)$ & $0.537(\mathrm{NS})^{\mathrm{c}}$ \\
\hline PROM, $n(\%)$ & $33(33.7)$ & $28(28.6)$ & $0.875(\mathrm{NS})^{\mathrm{c}}$ \\
\hline Clinical chorioamnionitis, $n(\%)$ & $18(18.4)$ & $16(16.3)$ & $0.850(\mathrm{NS})^{\mathrm{c}}$ \\
\hline \multicolumn{4}{|l|}{ Antenatal betamethasone } \\
\hline Two doses, $n(\%)$ & $39(39.8)$ & $36(36.7)$ & \multirow[t]{2}{*}{$0.646(\mathrm{NS})^{\mathrm{c}}$} \\
\hline Only one dose, $n(\%)$ & $11(11.2)$ & $14(14.3)$ & \\
\hline Intrapartum antibiotics, $n(\%)$ & $24(24.5)$ & $27(24.5)$ & $0.744(\mathrm{NS})^{\mathrm{c}}$ \\
\hline \multicolumn{4}{|l|}{ Mode of delivery } \\
\hline $\mathrm{SVD}, n(\%)$ & $44(44.8)$ & $41(41.8)$ & \multirow[t]{2}{*}{$0.777(\mathrm{NS})^{\mathrm{c}}$} \\
\hline Cesarean section, $n(\%)$ & $54(55.1)$ & $57(58.2)$ & \\
\hline \multicolumn{4}{|l|}{ Neonatal } \\
\hline Gestation (weeks), mean $\pm \mathrm{SD}$ & $30.9 \pm 2.9$ & $30.7 \pm 2.7$ & \multirow[t]{2}{*}{$0.493(\mathrm{NS})^{\mathrm{b}}$} \\
\hline Median (IQR) & $31(28-33)$ & $30(29-32)$ & \\
\hline$<28$ weeks, $n(\%)$ & $14(14.3)$ & $12(12.2)$ & \multirow[t]{5}{*}{$0.989(\mathrm{NS})^{\mathrm{c}}$} \\
\hline 28-31 weeks, $n(\%)$ & $44(44.9)$ & $47(48.0)$ & \\
\hline 32-33 weeks, $n(\%)$ & $28(28.6)$ & $28(28.6)$ & \\
\hline 34-36 weeks, $n(\%)$ & $9(9.2)$ & $8(8.2)$ & \\
\hline$\geq 37$ weeks, $n(\%)$ & $3(3.1)$ & $3(3.1)$ & \\
\hline Birth weight $(\mathrm{g})$, mean \pm SD & $1185 \pm 194$ & $1163 \pm 181$ & $0.414(\mathrm{NS})^{\mathrm{a}}$ \\
\hline$<1000 \mathrm{~g}, n(\%)$ & $19(19.4)$ & $17(17.3)$ & \multirow[t]{3}{*}{$0.845(\mathrm{NS})^{\mathrm{c}}$} \\
\hline $1000-1199 \mathrm{~g}, n(\%)$ & $39(39.8)$ & $44(44.9)$ & \\
\hline $1200-1499 \mathrm{~g}, n(\%)$ & $40(40.8)$ & $37(37.8)$ & \\
\hline Appropriate for gestational age, $n(\%)$ & $70(71.4)$ & $75(76.5)$ & \multirow[t]{3}{*}{$0.464(\mathrm{NS})^{\mathrm{c}}$} \\
\hline Small for gestational age, $n(\%)$ & $27(27.6)$ & $23(23.9)$ & \\
\hline Large for gestational age, $n(\%)$ & $1(1.0)$ & $0(0.0)$ & \\
\hline Male gender, $n(\%)$ & $54(55.1)$ & $56(57.1)$ & $0.775(\mathrm{NS})^{\mathrm{c}}$ \\
\hline \multicolumn{4}{|l|}{ APGAR score } \\
\hline 1 min, median (IQR) & $8(6-8)$ & $8(6-8)$ & $0.758(\mathrm{NS})^{\mathrm{b}}$ \\
\hline 5 min, median (IQR) & $9(8-9)$ & $9(7.75-9)$ & $0.622(\mathrm{NS})^{\mathrm{b}}$ \\
\hline Downe score at recruitment, median (IQR) & $5(5-7)$ & $5(5-7)$ & $0.850(\mathrm{NS})^{\mathrm{b}}$ \\
\hline $\mathrm{SpO}_{2}$ at recruitment, median (IQR) & $92(91-93)$ & $92(91-93)$ & $0.250(\mathrm{NS})^{\mathrm{b}}$ \\
\hline Surfactant replacement therapy, $n(\%)$ & $41(41.8)$ & $43(43.8)$ & $0.885(\mathrm{NS})^{\mathrm{c}}$ \\
\hline Paracetamol for hs-PDA, $n(\%)$ & $7(7.1)$ & $20(20.4)$ & 0.011 \\
\hline
\end{tabular}

${ }^{\text {a } I n d e p e n d e n t ~ s a m p l e s ~} T$ test

${ }^{\mathrm{b}}$ Mann-Whitney $U$ test

${ }^{\mathrm{c}}$ Fisher's exact test

$S D$ Standard deviation, IQR Inter Quartile Range, NS Not significant, $P I H$ Pregnancy-induced hypertension, $P O L$ Premature onset of labor, $P R O M$ Premature rupture of membrane, SVD Spontaneous vaginal delivery, LSCS Lower section cesarean section, $h s$-PDA Hemodynamically significant patent ductus arteriosus

sepsis and its associated complications. However, the median duration of hospital stay was longer in the placebo group compared with vitamin A (median (IQR), 14 (9-22) vs. 12
(9-15) days; $p<0.05)$. Three infants in vitamin A group and 2 in placebo group left against medical advice for financial/ personal reasons and could not be followed up. 
Table 2 Comparison of outcome variables

\begin{tabular}{|c|c|c|c|c|c|}
\hline Parameter & $\begin{array}{l}\text { Vitamin A } \\
(n=98)\end{array}$ & $\begin{array}{l}\text { Placebo } \\
(n=98)\end{array}$ & $\begin{array}{l}\text { Relative risk }(95 \% \\
\mathrm{CI})\end{array}$ & $P$ value & $\begin{array}{l}\text { NNT } \\
\text { (benefit) }\end{array}$ \\
\hline \multicolumn{6}{|l|}{ Primary outcome variable } \\
\hline $\begin{array}{l}\text { Composite incidences of all-cause mortality and oxygen requirement for } \\
28 \text { days, } \mathrm{n}(\%)\end{array}$ & $11(11.2)$ & $25(25.3)$ & $\begin{array}{l}0.440 \\
\quad(0.229-0.844)\end{array}$ & 0.013 & 7 \\
\hline \multicolumn{6}{|l|}{ Secondary outcome variables } \\
\hline Early onset sepsis*, $n(\%)$ & $11(11.2)$ & $10(10.2)$ & $\begin{array}{l}1.176 \\
(0.656-2.107)\end{array}$ & $\begin{array}{l}0.584 \\
(\mathrm{NS})\end{array}$ & \\
\hline Late onset sepsis*, $n(\%)$ & $9(9.2)$ & $18(18.4)$ & $\begin{array}{l}0.564 \\
(0.346-0.918)\end{array}$ & 0.021 & 6.686 \\
\hline $\begin{array}{l}\text { Superficial infections** } \\
n(\%)\end{array}$ & $4(4.1)$ & $7(7.1)$ & $\begin{array}{l}0.571 \\
(0.172-1.889)\end{array}$ & $\begin{array}{l}0.359 \\
(\mathrm{NS})\end{array}$ & - \\
\hline $\mathrm{NNH}, n(\%)$ & $74(75.5)$ & $73(74.5)$ & $\begin{array}{l}1.013 \\
(0.862-1.191)\end{array}$ & $\begin{array}{l}0.869 \\
(\mathrm{NS})\end{array}$ & - \\
\hline Shock, $n(\%)$ & $20(20.4)$ & $30(30.6)$ & $\begin{array}{l}0.667 \\
(0.407-1.090)\end{array}$ & $\begin{array}{l}0.106 \\
(\mathrm{NS})\end{array}$ & - \\
\hline Apnea, $n(\%)$ & $15(15.3)$ & $24(24.5)$ & $\begin{array}{l}0.625 \\
(0.349-1.117)\end{array}$ & $\begin{array}{l}0.113 \\
(\mathrm{NS})\end{array}$ & - \\
\hline $\mathrm{BPD}, n(\%)$ & $2(2.0)$ & $9(9.2)$ & $\begin{array}{l}0.222 \\
(0.049-1.000)\end{array}$ & $\begin{array}{l}0.050 \\
(\mathrm{NS})\end{array}$ & - \\
\hline \multicolumn{6}{|l|}{ Nature of BPD*** } \\
\hline Mild, $n(\%)$ & $2(2.0)$ & $5(5.1)$ & & & \\
\hline Moderate, $n(\%)$ & $0(0.0)$ & $3(3.1)$ & - & $\begin{array}{l}0.920 \\
(\mathrm{NS})^{\mathrm{c}}\end{array}$ & - \\
\hline Severe, $n(\%)$ & $0(0.0)$ & $1(1.0)$ & & & \\
\hline Incidence of death at 36 weeks, $n(\%)$ & $9(9.2)$ & $16(16.3)$ & $\begin{array}{l}0.562 \\
(0.262-1.211)\end{array}$ & $\begin{array}{l}0.141 \\
\text { (NS) }\end{array}$ & - \\
\hline hs-PDA, $n(\%)$ & $7(7.1)$ & $20(20.4)$ & $\begin{array}{l}0.350 \\
(0.155-0.789)\end{array}$ & 0.011 & 7.538 \\
\hline Feeding intolerance, $n(\%)$ & $6(6.1)$ & $10(10.2)$ & $\begin{array}{l}0.600 \\
(0.226-1.586)\end{array}$ & $\begin{array}{l}0.303 \\
\text { (NS) }\end{array}$ & - \\
\hline $\mathrm{NEC}, n(\%)$ & $1(1.0)$ & $4(4.1)$ & $\begin{array}{l}0.250 \\
(0.028-2.197)\end{array}$ & $\begin{array}{l}0.211 \\
\text { (NS) }\end{array}$ & - \\
\hline $\mathrm{IVH} \geq$ grade II, $n(\%)$ & $4(4.1)$ & $7(7.1)$ & $\begin{array}{l}0.571 \\
(0.172-1.889)\end{array}$ & $\begin{array}{l}0.359 \\
\text { (NS) }\end{array}$ & - \\
\hline Cholastatic jaundice, $n(\%)$ & $0(0.0)$ & $2(2.0)$ & $\begin{array}{l}0.200 \\
(0.009-4.113)\end{array}$ & $\begin{array}{l}0.296 \\
\text { (NS) }\end{array}$ & - \\
\hline AKI (serum creatinine $>1.5 \mathrm{mg} / \mathrm{dL}), n(\%)$ & $11(11.2)$ & $16(16.3)$ & $\begin{array}{l}0.687 \\
(0.336-1.405)\end{array}$ & $\begin{array}{l}0.304 \\
(\mathrm{NS})\end{array}$ & - \\
\hline $\begin{array}{l}\text { PVL, } n(\%) \\
\text { (moderate to severe) }\end{array}$ & $1(1.0)$ & $3(3.1)$ & $\begin{array}{l}0.333 \\
(0.035-3.149)\end{array}$ & $\begin{array}{l}0.337 \\
\text { (NS) }\end{array}$ & - \\
\hline Severe ROP requiring laser therapy, $n(\%)$ & $1(1.0)$ & $2(2.0)$ & $\begin{array}{l}0.500 \\
(0.046-5.424)\end{array}$ & $\begin{array}{l}0.568 \\
(\mathrm{NS})\end{array}$ & - \\
\hline
\end{tabular}

*Blood culture positive

**Superficial infections_-skin/mucosal infections, umbilical sepsis, conjunctivitis

***BPD classified as per severity at 36 weeks PMA

${ }^{\mathrm{c}}$ Fisher's exact test, IQR Inter quartile range

$C I$ Confidence interval, $n$ Number, $N S$ Not significant, $N N T B$ Number needed to treat for benefit, $N N H$ Neonatal hyperbilirubinemia (unconjugated), $B P D$ Bronchopulminary dysplasia, $h s-P D A$ Hemodynamically significant patent ductus arteriosus, $N E C$ Necrotising enterocolitis, $I V H$ Intraventricular hemorrhage, $A K I$ Acute kidney injury, $P V L$ Periventricular leucomalacia, ROP Retinopathy of prematurity

\section{Serum retinol concentration in study neonates}

Number of neonates with low serum retinol $(<20 \mu \mathrm{g} / \mathrm{dL})$ were high (over 60/98) in both the groups at baseline. A significant increase in mean serum retinol concentration was observed in vitamin A group at 28 days. Thirty-three
(33/98) neonates had low serum retinol concentrations in placebo compared with none in vitamin A group (RR (95\% CI), $0.014(0.001-0.240) ; p<0.01$, NNTB 2) (Table 4). None of the infants who received vitamin A had a high serum retinol concentration $(>100 \mu \mathrm{g} / \mathrm{dL})$ on day 28 of life. 
Table 3 Nature of respiratory support

\begin{tabular}{lllll}
\hline Characteristics & Vitamin A $(n=98)$ & Placebo $(n=98)$ & Relative risk (95\% CI) & $P$ value \\
\hline Oxygen supplementation by hood/nasal prongs, $n(\%)$ & $20(20.4)$ & $23(23.5)$ & $0.869(0.512-1.477)$ & $0.605(\mathrm{NS})$ \\
CPAP, $n(\%)$ & $68(69.38)$ & $65(66.3)$ & $1.046(0.863-1.269)$ & $0.646(\mathrm{NS})$ \\
HFNC, $n(\%)$ & $18(18.4)$ & $21(21.4)$ & $0.857(0.488-1.506)$ & $0.592(\mathrm{NS})$ \\
Duration of CPAP/HFNC (days), median (IQR) & $2.50(2.00-3.70)$ & $3.50(2.00-6.00)$ & - & $0.004^{\mathrm{b}}$ \\
MV, $n(\%)$ & $17(17.3)$ & $25(25.5)$ & $0.680(0.393-1.773)$ & $0.168(\mathrm{NS})$ \\
$\begin{array}{l}\text { Duration of MV (days) } \\
\text { median (IQR) }\end{array}$ & $4.50(2.75-6.50)$ & $4.30(2.25-10.50)$ & - & $0.877(\mathrm{NS})^{\mathrm{b}}$ \\
$\begin{array}{l}\text { Total duration of oxygen requirement (days) } \\
\text { median (IQR) }\end{array}$ & $4.35(3.48-6.25)$ & $5.65(4.48-8.95)$ & - & $<0.001^{\mathrm{b}}$ \\
\hline
\end{tabular}

${ }^{\mathrm{b}}$ Mann-Whitney $U$ test, $n$ Number

$C I$ Confidence interval, IQR Inter quartile range, NS Not significant, CPAP Continuous positive airway pressure, HFNC High flow nasal cannula, $M V$ Mechanical ventilation

\section{Kaplan Meier survival analysis}

Mean survival of vitamin A and placebo groups was 26.1 and 24.7 days, respectively. Log rank test failed to detect any statistically significant difference between the groups $\left(\chi^{2}=\right.$ 2.277; $p=0.131$ ) (Fig. 2).

\section{Discussion}

In the present study, a statistically significant reduction in composite incidence of all-cause mortality and oxygen requirement for 28 days was observed after oral VAS. Among secondary variables, duration of oxygen supplementation, non-invasive respiratory support, hospital stay, and incidences of LOS and hs-PDA also favored VAS. No major adverse effect of VAS was documented.

VAS in the neonatal period was initially proposed as a means to increase the body's vitamin A stores [18], and more recently as a strategy to improve infant survival [37]. Three trials, conducted in Indonesia, India, and Bangladesh, have shown a reduction in mortality during infancy after VAS during neonatal period [18, 23, 29].

Though a recent meta-analysis [11] demonstrated a marginal benefit of IM-VAS in VLBW in reducing mortality and oxygen requirement at 1 month (NNTB 20), and the risk of BPD at 36 weeks (NNTB 11) and benefits of enteral VAS in VLBW are not well explored yet. One randomized controlled trial (RCT) using a daily oral vitamin A (5000 IU/day) documented serum retinol concentrations similar to IM supplementation [25], no decrease in the incidence of BPD or death was

Table 4 Serum retinol concentration

\begin{tabular}{|c|c|c|c|c|c|}
\hline $\begin{array}{l}\text { Serum retinol } \\
(\mu \mathrm{g} / \mathrm{dL})\end{array}$ & $\begin{array}{l}\text { Vitamin A } \\
(n=98)\end{array}$ & $\begin{array}{l}\text { Placebo } \\
(n=98)\end{array}$ & $\begin{array}{l}\text { Relative risk } \\
(95 \% \mathrm{CI})\end{array}$ & $P$ value & NNT (benefit) \\
\hline $\begin{array}{l}\text { At recruitment } \\
\text { mean } \pm \mathrm{SD} \\
\text { median }(\mathrm{IQR})\end{array}$ & $\begin{array}{l}17.6 \pm 7.0 \\
16.8 \\
(12.5-23.3)\end{array}$ & $\begin{array}{l}17.5 \pm 6.7 \\
17.0 \\
(11.9-23.0)\end{array}$ & - & $0.933(\mathrm{NS})^{\mathrm{b}}$ & - \\
\hline $\begin{array}{l}\text { Neonates with low serum retinol } \\
(<20 \mu \mathrm{g} / \mathrm{dL}), n(\%)\end{array}$ & $61(62.2)$ & $63(64.3)$ & $\begin{array}{l}0.968 \\
(0.782-1.198)\end{array}$ & 0.767 (NS) & - \\
\hline $\begin{array}{l}\text { Neonates with very low serum retinol } \\
(<10 \mu \mathrm{g} / \mathrm{dL}), n(\%)\end{array}$ & $18(18.4)$ & $16(16.3)$ & $\begin{array}{l}1.125 \\
(0.609-2.075)\end{array}$ & $0.706(\mathrm{NS})$ & - \\
\hline $\begin{array}{l}\text { At day } 28 \text { of life, mean } \pm \text { SD } \\
\text { median (IQR) }\end{array}$ & $\begin{array}{l}74.9 \pm 16.9 \\
80.6 \\
(58.1-88.2) \\
(n=87)\end{array}$ & $\begin{array}{l}21.9 \pm 7.9 \\
21.7 \\
(15.1-26.8) \\
(n=80)\end{array}$ & - & $<0.001^{\mathrm{b}}$ & - \\
\hline $\begin{array}{l}\text { Neonates with low serum retinol } \\
(<20 \mu \mathrm{g} / \mathrm{dL}), n(\%)\end{array}$ & $0(0.0)$ & $33(33.7)$ & $\begin{array}{l}0.014 \\
(0.001-0.240)\end{array}$ & 0.003 & 2.339 \\
\hline $\begin{array}{l}\text { Neonates with very low serum retinol } \\
(<10 \mu \mathrm{g} / \mathrm{dL}), n(\%)\end{array}$ & $0(0.0)$ & $6(6.1)$ & $\begin{array}{l}0.076 \\
(0.004-1.347)\end{array}$ & $0.079(\mathrm{NS})$ & - \\
\hline
\end{tabular}

\footnotetext{
${ }^{\mathrm{b}}$ Mann-Whitney $U$ test, $n$ Number, IQR Inter quartile range, $N N T B$ Number needed to treat for benefit, $N S$ Not significant
} 


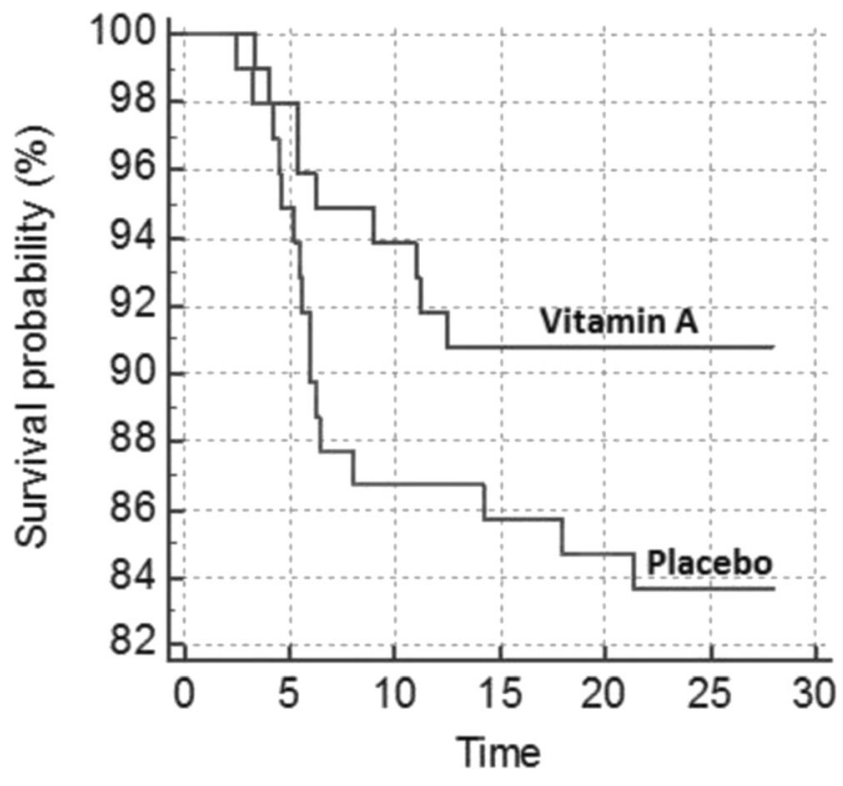

Fig. 2 Kaplan Meier survival analysis curve

documented [36]. The sample size of this study was less and many of the infants received postnatal steroids. Another RCT of oral vitamin A prophylaxis $(30,000 \mathrm{IU} / \mathrm{kg}$ for 6 weeks starting within first $48 \mathrm{~h}$ ) in infants of GA $\leq 32$ weeks and $\mathrm{BW} \leq 1250 \mathrm{~g}$ on oxygen support, did not find any significant difference in the incidences of RDS, LOS, PDA, pneumothorax, severe intracranial hemorrhage, ROP, BPD, and mortality [8].

One of the reasons for the lack of beneficial effects of oral VAS may be due poor bioavailability of vitamin A from oilbased solution. Immature gut in VLBW may lead to decreased hydrolysis of retinyl esters, poor availability of vitamin A carrier-proteins in enterocyte, and inadequate bile salts for micelle formation [15]. Absorption of vitamin A may be better from aqueous solution, as used in our study, as smaller particle size might have had better diffusion and better bioavailability [27].

Significantly lower incidence of LOS in vitamin A group may be due to better immune function after vitamin A supplementation [2]. Meta-analysis of three published trials showed a non-significant trend towards a reduction in culture-proven nosocomial sepsis [4, 22, 33]. Vitamin A is required in early gestation for normal cardiopulmonary development [26], and postnatally, it accelerates the development of oxygen induced contraction of the ductus arteriosus in the rat model [32], which might have contributed to the significantly lower incidence of hs-PDA found in this study. Another study did not find any difference in the spontaneous closure rate of hs-PDA by day 14 in ventilator-dependent preterm VLBW infants after IM VAS (2000-3000 IU/kg IM thrice weekly for 4 weeks) [31].

There is no "standard" regimen of oral VAS. Ambalavanan et al. [1] compared the "standard" IM regimen of VAS
(5000 IU for 3 doses/week for 4 weeks) [33], with a higher IM dose (10,000 IU 3 doses/week for 4 weeks) and a once weekly IM dose (15,000 IU/week for 4 weeks). Adverse effects were seen in less than $5 \%$. Higher dose did not increase retinol or improve outcome. Once weekly regimen led to lower serum retinol levels, but outcome was similar.

Adequate concentration of serum retinol in VLBW infants is not known. Concentrations below $20 \mu \mathrm{g} / \mathrm{dL}(0.70 \mu \mathrm{mol} / \mathrm{L})$ have been considered "deficiency" in premature infants, and concentrations below $10 \mu \mathrm{g} / \mathrm{dL}(0.35 \mu \mathrm{mol} / \mathrm{L})$ indicate severe deficiency and depleted liver stores $[11,33]$. In the present study, approximately $60 \%$ of study infants in both the groups had deficiency at baseline, but after VAS for 28 days, 33.7\% neonates in placebo group had deficiency compared to none in vitamin A group. A recent Indian study reported a very high rate of VAD (over 90\%) at birth in neonates of BW $<1250 \mathrm{~g}$ [14]. None of our study infants in vitamin A group had a high $(>100 \mu \mathrm{g} / \mathrm{dL}$ ) serum retinol concentration which could be considered as toxic level.

A reasonably large sample size, well-adhered study protocol and use of aqueous solution of vitamin A were the strengths of the present study. Major limitations were inclusion of relatively larger and more mature neonates, low rate of antenatal steroid coverage, lower requirement of $\mathrm{MV}$, and lack of long term follow-up.

To conclude, early postnatal oral VAS was associated with better composite outcome of all-cause mortality and oxygen requirement for 28 days in VLBW neonates with respiratory distress. In LMIC, where the burden of preterm/VLBW is high, oral VAS may be implemented as a cost-effective strategy to improve the clinical outcome in VLBW neonates with respiratory distress. However, long term follow-up is necessary to document the effect of high-dose VAS on respiratory, growth, and neurodevelopmental outcome.

Acknowledgments Vitamin A and placebo oral solutions were procured from the Apex Pharmaceuticals Private Limited, Chennai, India, though the manufacturer who did not have any control over study design or outcome.

Authors' contributions Prof Sriparna Basu and Prof Ashok Kumar conceptualized and designed the study, coordinated and supervised data collection, drafted the initial manuscript, and reviewed and revised the manuscript. Dr. Parul Khanna designed the data collection instruments, collected data, carried out the initial analyses, and reviewed and revised the manuscript. Dr. Ragini Srivastava supervised the data collection, did the biochemical analysis, reviewed and revised the manuscript. All authors approved the final manuscript as submitted and agree to be accountable for all aspects of the work.

\section{Compliance with ethical statements}

Conflict of interest The authors declare that they have no conflict of interest.

Ethical approval The trial was ethically approved by the Institute Ethics Committee of All India Institute of Medical Sciences, Rishikesh, India. 
Informed consent Informed consent was obtained from all individual participants included in the study.

\section{References}

1. Ambalavanan N, Wu TJ, Tyson JE, Kennedy KA, Roane C, Carlo WA (2003) A comparison of three vitamin A dosing regimens in extremely-low-birth-weight infants. J Pediatr 142:656-661

2. Bates CJ (1995) Vitamin A. Lancet 345:31-35

3. Beam KS, Aliaga S, Ahlfeld SK, Cohen-Wolkowiez M, Smith PB, Laughon MM (2014) A systematic review of randomized controlled trials for the prevention of bronchopulmonary dysplasia in infants. J Perinatol 34:705-710

4. Bental RY, Cooper PA, Cummins RR, Sandler DL, Wainer S, Rotschild A (1994) Vitamin A therapy - effects on the incidence of bronchopulmonary dysplasia. Afr J Food Agric Nutr Dev 6:141-145

5. Bessey OA, Lowry OH, Brock MJ, Lopez JA (1946) The determination of vitamin $A$ and carotene in small quantities of blood serum. J Biol Chem 166:177-188

6. Blencowe H, Cousens S, Chou D, Oestergaard M, Say L, Moller AB, Kinney M, Lawn J, Born Too Soon Preterm Birth Action Group (2013) Born too soon: the global epidemiology of 15 million preterm births. Reprod Health 10:S2

7. Bolisetty S, Osborn D, Sinn J, Lui K, Australasian Neonatal Parenteral Nutrition Consensus Group (2014) Standardized neonatal parenteral nutrition formulations - an Australasian group consensus 2012. BMC Pediatr 14:48

8. Calisici E, Yarci E, Degirmencioglu H, Oncel MY, Oguz SS, Uras N, Dilmen U (2014) PO-0731 the effects of early oral vitamin A treatment on the prevention of bronchopulmonary dysplasia in low birth weight infants. Arch Dis Child 99:A494

9. Chytil F (1992) The lungs and vitamin A. Am J Phys 262:L517L527

10. Couroucli XI, Placencia JL, Cates LA, Suresh GK (2016) Should we still use vitamin a to prevent bronchopulmonary dysplasia? J Perinatol 36:581-585

11. Darlow BA, Graham PJ, Rojas-Reyes MX (2016) Vitamin A supplementation to prevent mortality and short- and long-term morbidity in very low birth weight infants. Cochrane Database of Syst Rev 8:CD000501

12. Downes JJ, Vidyasagar D, Morrow GM, Boggs TR Jr (1970) Respiratory distress syndrome of newborn infants. Clin Pediatr 9: 325-331

13. Gawronski CA, Gawronski KM (2016) Vitamin A supplementation for prevention of bronchopulmonary dysplasia: cornerstone of care or futile therapy. Ann Pharmacother 50:680-684

14. Giridhar S, Kumar J, Attri SV, Dutta S, Kumar P (2019) Intramuscular followed by oral vitamin A supplementation in neonates with birth weight from 750 to $1250 \mathrm{~g}$ : a randomized controlled trial. Ind J Clin Biochem First Online 03 Januaryhttps:// doi.org/10.1007/s12291-018-0807-1

15. Goncalves A, Roi S, Nowicki M, Dhaussy A, Huertas A, Amiot MJ, Reboul E (2015) Fat soluble vitamin intestinal absorption: absorption sites in the intestine and interactions for absorption. Food Chem 172:155-160

16. Guimaraes $\mathrm{H}$, Guedes MB, Rocha G, Tome T, Albino-Teixeira A (2012) Vitamin A in prevention of bronchopulmonary dysplasia. Curr Pharm Des 18:3101-3113

17. Haider BA, Sharma R, Bhutta ZA (2017) Neonatal vitamin A supplementation for the prevention of mortality and morbidity in term neonates in low and middle income countries. Cochrane Database of Syst Rev 2:CD006980

18. Humphrey JH, Agoestina T, Wu L, Usman A, Nurachim M, Subardja D, Hidayat S, Tielsch J, West KP Jr, Sommer A (1996)
Impact of neonatal vitamin A supplementation on infant morbidity and mortality. J Pediatr 128:489-496

19. International committee (1984) An international classification of retinopathy of prematurity. Br J Ophthalmol 68:690-697

20. Jobe AH, Bancalari E (2001) Bronchopulmonary dysplasia. Am J Respir Crit Care Med 163:1723-1729

21. Kennedy KA, Stoll BJ, Ehrenkranz RA, Oh W, Wright LL, Stevenson DK, Lemons JA, Sowell A, Mele L, Tyson JE, Verter J (1997) Vitamin A to prevent bronchopulmonary dysplasia in very-low birth-weight infants: has the dose been too low? The NICHD Neonatal Research Network. Early Hum Dev 49:19-31

22. Kiatchoosakun $P$, Jirapradittha J, Panthongviriyakul MC, Khampitak T, Yongvanit P, Boonsiri P (2014) Vitamin A supplementation for prevention of bronchopulmonary dysplasia in verylow-birth-weight premature Thai infants: a randomized trial. J Med Assoc Thail 97:S82-S88

23. Klemm RD, Labrique AB, Christian P, Rashid M, Shamim AA, Katz J, Sommer A, West KP Jr (2008) Newborn vitamin A supplementation reduced infant mortality in rural Bangladesh. Pediatrics 122:e242-e250

24. Koletzko B, Goulet O, Hunt J, Krohn K, Shamir R, Parenteral Nutrition Guidelines Working Group (2005) Guidelines on paediatric parenteral nutrition of the European society of paediatric gastroenterology, hepatology and nutrition (ESPGHAN) and the European society for clinical nutrition and metabolism (ESPEN), supported by the European society of paediatric research (ESPR). J Pediatr Gastroenterol Nutr 41:S47-S53

25. Landman J, Sive A, Heese HD, Van der Elst C, Sacks R (1992) Comparison of enteral and intramuscular vitamin A supplementation in preterm infants. Early Hum Dev 30:163-170

26. Mactier H, Weaver LT (2005) Vitamin A and preterm infants: what we know, what we don't know, and what we need to know. Arch Dis Child Fetal Neonatal Ed 90:F103-F108

27. Morales S, Chung AW, Lewis JM, Messina A, Holt LE Jr (1950) Absorption of fat and vitamin A in premature infants: II effect of particle size on the absorption of these substances. Pediatrics. 6: 644-649

28. Papile LA, Burstein J, Burstein R, Koffler H (1978) Incidence and evolution of subependymal and intraventricular hemorrhage: a study of infants with birth weights less than 1,500 gm. J Pediatr 92:529-534

29. Rahmathullah L, Tielsch JM, Thulasiraj RD, Katz J, Coles C, Devi S (2003) Impact of supplementing newborn infants with vitamin A on early infant mortality: community based randomised trial in southern India. BMJ 327:254-250

30. Rakshasbhuvankar A, Patole S, Simmer K, Pillow JJ (2017) Enteral vitamin A for reducing severity of bronchopulmonary dysplasia in extremely preterm infants: a randomised controlled trial. BMC Pediatr 17:204

31. Ravishankar C, Nafday S, Green RS, Kamenir S, Lorber R, Stacewicz-Sapuntzakis M, Bridges ND, Holzman IR, Gelb BD (2003) A trial of vitamin A therapy to facilitate ductal closure in premature infants. J Pediatr 143:644-648

32. Shaul PW (2001) Maternal vitamin A administration and the fetal ductus arteriosus. Pediatr Res 49:744-746

33. Tyson JE, Wright LL, Oh W, Kennedy KA, Mele L, Ehrenkranz RA, Stoll BJ, Lemons JA, Stevenson DK, Bauer CR, Korones SB, Donovan EF, Carlo WA, Shankaran S, Stark AR, Papile LA, Jobe A, Stacewicz-Sapuntzakis M, Verter J, Fanaroff AA (1999) Vitamin A supplementation for extremely-low-birth-weight infants: National Institute of Child Health and Human Development neonatal research network. N Engl J Med 340:1962-1968

34. Uberos J, Miras-Baldo M, Jerez-Calero A, Narbona-López E (2014) Effectiveness of vitamin A in the prevention of complications of prematurity. Pediatr Neonatol 55:358-362 
35. Villar J, Giuliani F, Fenton TR, Ohuma EO, Ismail LC, Kennedy SH, INTERGROWTH-21st Consortium (2016) INTERGROWTH-21st very preterm size at birth reference charts. Lancet 387:844-845

36. Wardle SP, Hughes A, Chen S, Shaw NJ (2001) Randomised controlled trial of oral vitamin A supplementation in preterm infants to prevent chronic lung disease. Arch Dis Child Fetal Neonatal Ed 84: F9-F13

37. WHO (1996) Indicators for assessing vitamin A deficiency and their application in monitoring and evaluation intervention programmes. World Health Organization, Geneva
38. World Health Organization (2009) Global prevalence of vitamin A deficiency in populations at risk 1995-2005. In: WHO Global Database on Vitamin A Deficiency. WHO, Geneva

Publisher's note Springer Nature remains neutral with regard to jurisdictional claims in published maps and institutional affiliations. 